\title{
ENTORN DE L'OCUPACIÓ DE CÀRRECS PÚBLICS I DE LA PRÀCTICA D'OFICIS ARTESANS PER PART DELS CLERGUES EL SEGLE XIV ${ }^{1}$
}

\author{
JOSEFINA MUTGÉ I VIVES \\ Institució Milà i Fontanals \\ (CSIC, Barcelona)
}

SUMARI

1. Els clergues i els càrrecs públics.- 2. Els clergues en el govern de les ciutats.- 3. Els clergues i la pràctica d'oficis artesans.

Entre els diversos grups socials existents a l'època medieval, la clerecia era, sens dubte, el que presentava una major homogeneïtat pel que fa a la seva mentalitat col-lectiva. Malgrat això, era el que menys podia ser considerat com una veritable classe social perquè el constituien persones de les més diverses procedències, des del camperol fins a la família reial. Però, tot i que la cultura, la situació econòmica i la categoria social eren molt distintes, el clericat tingué en un grau molt més alt que altres classes socials l'esperit de cos privilegiat, d'estament, la qual cosa el distingí de la resta de la societat amb la qual convivia ${ }^{2}$.

\footnotetext{
'Oferim aquest treball a la Memòria de la que fou bona amiga i companya durant gairebé trenta anys, la Dra. Regina Sáinz de la Maza Lasoli.

Les abreviatures utilitzades són: $\mathrm{ACA}=$ Arxiu de la Corona d'Aragó; $\mathrm{AHCB}=\mathrm{Arxiu}$ Històric de la Ciutat de Barcelona; $\mathrm{C}=$ Cancelleria; col.=columna; fol. fols. = foli, folis; $\mathrm{p}$., $\mathrm{pp} .=$ pàgina, pàgines; $\mathrm{r} .=$ recto; reg. $=$ registre; v. =verso.

${ }^{2} \mathrm{~S}$. SOBREQUÉs, La época del patriciado urbano, p. 163.

"Anuario de Estudios Medievales". 28 (1998)
} 
Si observem la relació entre la societat eclesiàstica i la civil a l'Edat Mitjana, ens adonem que, entre l'una i l'altra, hi havia diferents punts de fricció. Ens hi fixarem en tres d'importants: l'exercici de càrf́ecs públics per part dels clergues; les competències entre les autoritats laiques i eclesiàstiques en l'aspecte judicial; i l'exempció d'impostos per part de la clerecia. Aquí, ens ocuparem del primer d'aquests dos punts. Dels altres dos, en tractem en un altre treball que es publica al volum en Homenatge a la Memòria de la Professora de la Universitat de Saragossa, Carmen Orcastegui, també prematurament traspassada ${ }^{3}$.

\section{Els CLERGUES I ELS CÀRRECS PÚBlicS}

Una qüestió en la qual els sobirans catalano-aragonesos del segle XIV es veieren obligats a intervenir fou el de l'ocupació de càrrecs públics per part dels clergues.

Si mirem enrera en el temps, observem que, a partir del segle XII, hi havia una important presència de clergues o clerici intervenint en diferents instàncies: actuaven com a jutges o notaris, ja que, llavors, tot el saber era només a les seves mans. Però, a poc a poc, l'aparició de les ciutats i de les universitats, l'augment del poder de la monarquia i la penetració de les idees del Dret comú varen fer que les circumstàncies anessin canviant a favor dels laics. Per exemple, en els tribunals de justícia, veiem que es produí la substitució progressiva dels clergues per jutges laics de formació universitària; i el notariat, des de la segona meitat del segle XIII, anà passant, també progressivament, de les mans dels clergues a les mans dels laics ${ }^{4}$.

Per altra banda, la missió pròpia de la clerecia era el servei de Déu. La norma dictada per Sant Pau segons la qual "la milícia de Déu havia d'abstenir-se de tots els negocis del segle" era constantment recordada pels

\footnotetext{
'En premsal a "Aragón en la Edad Media", ed. per la Universitat de Saragossat.

${ }^{4}$ Aquesta yüestió és analitzada en profunditat per M.T. FERRER I MALLOL. Notariat laic contra notariat eclesiàstic. Un episodi de la pugna entre ambdós a Girona (1347-1380). "Estudios Historicos i Documentos de los Archivos de Protocolos", V (1977), pp. 19-34. La progressiva substitució dels notaris i escrivans eclesiàstics per notaris i escrivans laics és estudiada també amb detall per Rafael CONDE Y DELGADO DE MOLINA en un treball titulat La titularidad de las notarias parroquiales catalanas descle Pedron (III) el Grande a Jaime II: del Provecto Besalai (1281) a la Pragmática de 1302. "Estudis sobre Historia de la institució notarial a Catalunya en honor de Raimon Noguera". coord. per J.M. SANS I TRAVÉ. Barcelona. 1988. pp. $31-50$.
} 
pontífexs. Els clergues havien d'ocupar-se només dels afers pertocants a l'Església i a les miserabiles personae. Així, doncs, els era prohibit d'ocupar càrrecs $\mathrm{i}$ actuar com a advocats, notaris, actors, soldats, comandants d'esquadres, cirurgians i metges. Tampoc no podien dedicar-se a oficis artesanals. L'única feina permesa als clergues que no poguessin viure tan sols de l'altar era el treball de la terra, bé que només hi podien dedicar els moments d'oci que els permetia el ministeri sacerdotal ${ }^{5}$. Pel que fa a la Corona d'Aragó, el Concili Provincial de Lleida del 1229, que traslladà al context de la Tarraconense les decisions preses al Concili Laterà IV del 1215, prohibí que els clergues exercissin oficis o activitats seculars, especialment les deshonestes. En canvi, el Concili de Tarragona del 1239 (deu anys més tard) només vedà l'exercici de càrrecs laics, com batllies o vegueries, als eclesiàstics que tenien encomanada la cura d'ànimes o dignitats".

Els sacerdots ordenats, dedicats a l'altar, ja no solien exercir càrrecs públics. Però una major problemàtica es produïa amb els anomenats llavors clergues tonsurats.

Abans de seguir endavant, farem un breu comentari sobre la tonsura.

La tonsura era una cerimònia religiosa, establerta per l'Església, consistent a tallar els cabells i la barba a les persones que volien ser admeses a l'estat clerical, disposant-los per a rebre els Ordes Sagrats. Diferents concilis varen legislar sobre les característiques, forma i dimensions de la tonsura? ${ }^{7}$. Aquells qui havien estat tonsurats gaudien de privilegis, tant d'honorífics com d'útils. Entre aquests darrers, hi havia el de participar en

\footnotetext{
5Gabriel LE BRAS, La Iglesia Medieval. en "Ilistoria de la Iglesia. De los origenes a nuestros dias". dirigida por Agustín Fliche y Victor MARTIN. Edición española bajo la

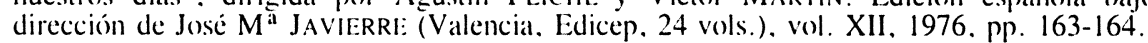

"J.M. PONS Gurı. Constitucions. Conciliars Tarraconenses (1228-1330). "Analecta Sacra Tarraconensia". XLVII (1974).pp. 65-128 i XI.VIII (1975).pp. 241-363: Maria Teresa FerRER I Malloo. L'expansió d'una regalia al començament del segle XIV: el notariat reial. "Estudis Historics i Documents dels Arxius de Protocols". XIII (Barcelona, Col-legi de Notaris. 1995). p. 58 i nota 10.

${ }^{7}$ Dictionnaire de Droit Canonique. Publié sous la direction de N. NAZ (7 vols.. Paris, 19351965), vol. 7 pp. 1290-1294. Cf. també Diccionario de Ciencias Eclesiásticas, publicada por Niceto Alonso Perujo y Juan PEREz Angulo (10 vols.. Barcelona, Libr. Subirana Hnos, ed., 1883-1890). vol. X. 1890 p. 191. D’aquesta qüestió i de molts aspectes referents a la clerecia del bisbat de Barcelona els segles XIII i XIV en tracta una magistral tesi doctoral. defensada a la Universitat de Barcelona el 22 de gener de 1999. L'autor és Josep BAUCELls i REIG, i es titula Vida y prictica religiosa én el obispado de Barcelona de 1229 a 1344. L'esmentada tesi hat estat dirigida pel Dr. Manuel RIU.
} 
els delmes i de poder obtenir un benefici eclesiàstic. A més dels privilegis, els clergues gaudien també d'exempcions: així, per exemple, s'alliberaven de formar part del servei d'host com també de les càrregues municipals i fiscals ${ }^{8}$.

Cal remarcar que la tonsura no era un Orde Sagrat sinó un ritu de la classe anomenada dels sagramentals, l'administració del qual era efectuada pels bisbes, pels cardenals i pels abats ${ }^{9}$. La ceriònia es podia efectuar en qualsevol moment de l'any litúrgic, en una església: després de l'Introito o bé del Kyrie de la missa, el celebrant tallava la barba i els cabells de l'impetrant, el qual pronunciava, juntament amb ell, les paraules de l'oblació ${ }^{10}$,

Molts clergues no passaven de la situació de tonsurats, per manca d'una vocació superior que potser mai no havien tingut. Pel fet d'haver-se produit abusos com el de demanar la tonsura només per a poder obtenir un benefici eclesiàstic, sense cap intenció de rebre els altres Ordes Sagrats, l'Església disposà que es conferís només a aquells que tenien el propòsit d'accedir al sacerdoci ${ }^{11}$.

Igual com succeïa amb els clergues ordenats, als tonsurats també els era prohibit d'exercir com a escrivans, advocats, notaris, però, a la pràctica, un gran nombre d'aquells, sense fer cas d'aquesta prohibició, ocupaven aquests llocs. Les autoritats civils es miraven aquesta situació amb recel, pel fet que les esmentades persones, si cometien alguna falta o infracció, sota el pretext d'estar en possessió de la tonsura, eludien la jurisdicció reial i s'alliberaven de les penes merescudes pels seus delictes. Per tal d'evitar això, la Corona anà promulgant algunes disposicions que, de l'una banda, assignaven a la jurisdicció civil tot allò que no era pròpiament eclesiàstic i, de l'altra, posaven obstacles al funcionament de les notaries eclesiàstiques exercides per tonsurats ${ }^{12}$. El pas més important el donà Jaume II l'any 1302 promulgant una pragmàtica que prohibia que els clergues redactessin instruments i que accedissin al tabel·lionat. Quedaven exceptuats d'aquesta

\footnotetext{
${ }^{8}$ Dictionnaire de Droit Canonique, cit., 7, col. 1290-1291 (tonsure). Cf. també Gabriel LE BRAS, La Iglesia Medieval, p. 154.

${ }^{9}$ Ibidem.

${ }^{10}$ Diccionario de Ciencias Eclesiásticas, por N.A. Perujo y J. PÉrez Angulo, cit., p. 191.

"Dictionnaire de Droit Canonique, cit, 7 (tonsure), col. 1292. Vegeu, també, J. BauCELLS, Vida y práctica religiosa en el obispado de Barcelona, cit. (tesi doctoral inèdita), pp. $2707 \mathrm{i}$ ss.

${ }^{12}$ M.T. FERrER, L'expansió d'una regalia al començament del segle XIV, cit., p. 58.
} 
disposició els clergues que ja tinguessin drets adquirits en escrivanies annexes a esglésies o altres institucions eclesiàstiques. Aquests podrien autoritzar escriptures si ho feien personalment, però no podrien delegar les funcions en un altre clergue sinó en un escrivà laic ${ }^{13}$. Aquest tema fou objecte d'una altra pragmàtica de Jaume II, del 25 de setembre de 1312 , segons la qual es rebutjava l'accés dels clergues ordenats i també dels clergues tonsurats a qualsevol ofici públic, no tan sols a les notaries. El motiu per a la publicació d'aquesta pragmàtica era el mateix que s'havia esgrimit per a l'anterior: que quan els clergues delinquien en l'exercici d'aquests oficis, eludien la justícia reial, més severa, i es refugiaven en l'eclesiàstical4.

El successor de Jaume II, Alfons el Benigne, no féu més que continuar la política del seu pare en aquesta qüestió. Insistí en les mateixes prohibicions establertes per Jaume II, la qual cosa demostrava que no es complien. Així, el 22 de juny de 1328, a fi de corregir la "insolència i malícia" del clericat, el rei Benigne ordenà al veguer i al batlle de Barcelona que no admetessin les persones tonsurades per a cap càrrec públic ("ne in civitatibus, villis seu locis quibus presunt, aliquem habentem seu portantem coronam in dictis officiis eligantur seu assumantur") i, per tal d'evitar que es cometessin fraus, aquells que haguessin estat elegits per a algun d'aquests càrrecs haurien de prestar jurament que no portaven corona i els infractors haurien de ser castigats. Els va ordenar, així mateix, que actuessin contra els falsos clergues i els traguessin la tonsura. Finalment, establí que cap dels seus súbdits no podia acudir al jutge eclesiàstic en qüestions relatives a la jurisdicció reial ${ }^{15}$. Això va provocar desconcert entre els tonsurats, com ho demostra, per exemple, el cas protagonitzat per un tal Bernat Forcadell, veí de Morvedre. Aquest personatge, acatant la disposició de Jaume II, va prometre, en aquell moment, que mai no al legaria un privilegi clerical $\mathrm{i}$, amb aquesta condició, fou admès com a jurat de l'esmentada vila de Morvedre; però, posteriorment, temia que, segons l'ordinació d'Alfons el

\footnotetext{
${ }^{13}$ J.M. PONS GURI, Constitucions, vol. 2, llib I, tít. V, c. I. Vegeu també M.T. FERrER, Notariat laic contra notariat eclesiàstic. cit., p. 20; IDEM, L'expansió d'una regalia, cit, p. 59 i nota 11 .

${ }^{14}$ J.M. POnS Guri, Constitucions, cit., llib. I, tít. V. c. 2; M.T. Ferrer, L'expansió d'una regalia al començament del segle XIV, cit., p. 59 i nota 12. La Dra. Ferrer ha localitzat aquesta pragmàtica a l'ACA: C, reg. 240 , fols. 83 v. -84 r.

${ }^{15}$ AHCB, Llibre Vert, I, fols. 327 v., col. 1-328 r., col. 2; ACA, C, reg. 519, fols. 148 v.-149 r (1328, junio, 22).
} 
Benigne, el batlle de Morvedre l'expulsés del seu ofici. El rei, atès que Forcadell ja s'havia compromès a no al-legar cap privilegi clerical i que, a més, no ostentava la tonsura, el 6 d'agost de 1328, ordenà al batlle que fos mantingut com a jurat de la dita vila ${ }^{16}$

Per tal d'evitar aquestes situacions ambigües, dos mesos més tard, el 20 d'agost de 1328, des de la localitat de Daroca, Alfons el Benigne promulgà diversos aclariments a la pragmàtica del 22 de juny anterior. Foren els següents:

1. Els clergues no casats, que haguessin estat tonsurats, malgrat que no ostentessin la tonsura i visquessin laicament, no podrien ser admesos ni elegits per a oficis del tabel·lió, de la jurisdicció ordinària, assessoria o bé del govern de les ciutats o viles, ja que l'exercici d'aquests oficis era prohibit als clergues.

2. Aquesta mateixa norma havia d'aplicar-se als clergues casats que ostentessin la tonsura i portessin vestidures clericals.

3. Els clergues casats que visquessin laicament podrien ser elegits per a exercir aquests càrrecs, bé que haurien de comprometre's davant dels oficials del lloc que, si cometien qualsevol falta, no al·legarien cap privilegi clerical sinó que acceptarien de ser jutjats per jutges laics, sota la pena del pagament a l'erari regi d'una multa de 500 monedes d'or.

4. Aquestes ordinacions no tan sols s'havien redactat per ser aplicades en un futur pròxim sinó que ja tenien vigència per als eclesiàstics que en aquells moments ocupaven algun càrrec; així, els clergues no casats i tonsurats, malgrat que no ostentessin la tonsura, i els casats que portessin tonsura i vestits clericals s'haurien de veure privats dels càrrecs públics. En quedaven, però, exceptuats els clergues solters o els casats amb muller verge o que aquesta ja hagués mort, que es manifestessin sense tonsura i visquessin laicament, els quals podien continuar desenvolupant els oficis que ja exercien, sempre que es comprometessin a no fer ús del privilegi clerical, com en el cas dels clergues casats.

5. Els clergues que haguessin tingut una única muller verge, que ja s'hagués mort, aquests podien continuar en els llocs que regentaven en vida de la seva muller, comprometent-se, això sí, a no usar del privilegi clerical.

6. Les notaries i escribanies de les esglésies - segons el rei Benigne- podien ser exercides per clergues o laics indistintament, respectant

\footnotetext{
${ }^{16}$ ACA. C. reg. 431, fol. 190 r. 1328, agost. 6.
} 
així l'ordinació del rei Pere el Gran, avi seu, i com havia estat sempre acostumat ${ }^{17}$.

L'endemà mateix de la redacció d'aquestes disposicions, el dia 21 d'agost, el rei Alfons el Benigne comunicava a Arnau Mansa, vicari del bisbe de Barcelona, que la disposició, segons la qual les notaries i les escrivanies de les esglésies podien ser ocupades per clergues o per laics, la matisaria la propera vegada que es traslladés a Barcelona, per tal de no perjudicar les llibertats de l'Església ${ }^{18}$.

Poc després, el 23 de setembre de 1328, a petició dels notaris de Barcelona, el rei va rebaixar la multa als qui infringissin la pragmàtica del 20 d'agost, des de les 500 monedes d'or fins a 2.000 sous barcelonesos, ja que aquella quantitat era considerada massa onerosa pels esmentats notaris ${ }^{19}$. La mateixa petició varen fer els corredors de Barcelona, als quals el Benigne també rebaixà la pena a 2.000 sous barcelonesos ${ }^{20}$. I el 26 d'octubre de 1328, ho demanaren els advocats i així mateix els fou atorgat $^{21}$. Ara bé, a cap d'aquests grups no els seria disminuïda aquesta quantitat si el que pretenien era eludir la jurisdicció reial i al-legar algun privilegi clerical.

Durant els anys que seguiren a la promulgació d'aquests aclariments a la pragmàtica, encara regnà un període de gran desorientació, tant per part dels afectats com dels oficials reials com de la mateixa Corona que, a voltes, queia en contradiccions, concedint a determinades persones allò que, segons les ordinacions, els era prohibit.

Després de les ordinacions del 20 d'agost de 1328, la Corona havia deixat ben clar -com hem vist més amunt- que els tonsurats solters, malgrat no manifestessin la tonsura i visquessin com a laics no podien ser admesos per als càrrecs, com tampoc no podien ser-ho els tonsurats casats que ostentessin la tonsura i portessin vestits clericals; en canvi, els tonsurats casats, que visquessin laicament i no ostentessin la tonsura ni els hàbits

\footnotetext{
${ }^{17}$ AHCB. Llibre Vert. I. fol. 328 r. col. 2; ACA, C, reg. 520 , fols. 174 r.-174 v. (1328, agost. 20)

${ }^{18} \mathrm{ACA}, \mathrm{C}$, reg. 520, fols. 176 v.-177 r. (1328, agost. 21).

${ }^{19} \mathrm{ACA}, \mathrm{C}$, reg. 520, fol. $190 \mathrm{r}$. (1328, setembre, 23). Aquesta mitigació de la pena fou feta també extensiva als notaris de Cervera (ACA. C. reg. 520, fols. 192 v.-193 v. 1328, octubre. 24).

20ACA. C, reg. 520. fols. 199 v.-200 (1328, octubre, 12).

${ }^{2}$ ACA. C, reg. 520, fols. 220 r.-v. (1328, octubre, 26).
} 
clericals, podien exercir els càrrecs, amb la condició de comprometre's a no acollir-se a cap privilegi eclesiàstic, sota el pagament de la corresponent multa per a als qui no ho complissin. Doncs bé, posarem alguns exemples de casos concrets que apareixen dins els registres de la cancelleria reial de l'Arxiu de la Corona d'Aragó, que ens permeten de constatar dos fets:

Primer: que els sobirans havien de confirmar en els càrrecs d'advocats o de notaris aquells que ja els ocupaven i que temien ésser-ne destituïts pels oficials reials els quals, complint la lletra de la pragmàtica, podien expulsar-los, o bé rebutjar-los si es tractava d'un ofici de nova creació; i

Segon: que el que s'esdevingué, en diverses ocasions, fou que els tonsurats solters que, en principi, no havien de ser admesos de cap manera en els càrrecs, si prestaven el jurament de no acollir-se als privilegis clericals, i si el rei ho volia, podien també exercir-los, com ho feien els tonsurats casats.

Entre els exemples del primer dels fets, de l'època d'Alfons el Benigne, tenim el del ciutadà de Barcelona, Gispert Riba, jurisperit casat, que vivia laicament $\mathrm{i}$ que, havent estat tonsurat, temia no poder exercir el seu ofici de jutge i d'advocat, malgrat que no incorria pas en la prohibició de la pragmàtica. En aquesta situació d'incertesa, va recórrer a Alfons el Benigne i, el 26 d'octubre de 1330, aquest sobirà ordenà al veguer i al batlle de Barcelona, que reconeguessin a Gispert Riba, com a jutge i advocat ${ }^{22}$.

El cas següent és com l'anterior. Francesc Puig, jurisperit de Barcelona, temorós de no poder actuar com a jutge i advocat per haver rebut la tonsura, també demanà ajut al rei Alfons el Benigne, el qual, el 2 de juliol de 1331, manà al veguer $\mathrm{i}$ al batlle de Barcelona que l'admetessin en la professió, sense posar-li cap objecció, ja que Puig, si bé havia estat tonsurat, era casat, no ostentava la tonsura i vivia com un laic; per consegüent, no incorria en la prohibició vigent ${ }^{23}$.

Dintre la segona de les situacions, tenim el cas de Joan Salat. Salat era un tonsurat no casat, bé que no mostrava la tonsura. Havia estat constituit com a notari públic el 2 de maig de 1331, és a dir, amb posterioritat a la publicació de la pragmàtica. D'acord amb aquesta, no podia ser admès per a exercir com a notari, però com que el rei tenia especial interès

\footnotetext{
22 ACA, C, reg. 440, fols. 187 v.-188r

${ }^{23} \mathrm{ACA}, \mathrm{C}$, reg. 446 , fol. 19 v.
} 
que accedís al tabel·lió, el dia 8 de juny de 1331, obligà als oficials reials de Barcelona a acceptar-lo com a notari, amb l'obligació de prometre que mai no s'acolliria a cap privilegi clerical ${ }^{24}$.

Un cas semblant al de Joan Salat fou el de Guillem Bramon, tonsurat i no casat. No podia, per tant, exercir de notari. Però, el 22 d'agost de 1333, el rei novament ordenà al veguer i batlle de Barcelona que l'admetessin al tabel-lió, prestant, això sí, el jurament de no acollir-se als privilegis de la clerecia, si cometia alguna infracció 25 .

Els primers anys del seu regnat, Pere el Cerimoniós va actuar d'una manera molt similar al seu pare en aquestes qüestions. Moltes vegades va haver d'ordenar al veguer i al batlle de Barcelona que, malgrat la normativa vigent, permetessin que molts tonsurats continuessin exercint el seu ofici d'advocat o bé de notari, si prestaven el repetit jurament, ja que els oficials reials s'hi oposaven. En el cas dels tonsurats solters, tot i ser-los prohibit l'exercici de l'abogacia o de la notaria, les practicaven, si el rei així ho volia, prestant el jurament. És a dir, en aquests primers anys del regnat de Pere el Cerimoniós, succeïa el mateix que durant el regnat d'Alfons el Benigne. En donarem alguns exemples:

El 2 de maig de 1336, Pere el Cerimoniós confirmà Guillem Vila, ciutadà de Barcelona, com a notari. Vila era tonsurat solter, però no ostentava tonsura. Prestant el jurament, també va ser admès ${ }^{26}$.

En la mateixa situació de Guillem Vila es trobaven els ciutadans de Barcelona, Jaume Canal i Pere Pla, tots dos tonsurats solters. Canal havia estat constituït com a notari el $1^{\mathrm{r}}$ d'abril de 1336 i Pla ho havia estat el 21 d'octubre de 1336. Tant l'un com l'altre estaven compresos en la prohibició, però el rei tenia especial interès que fossin admesos. Varen prestar el jurament $\mathrm{i}$, amb aquest requisit, foren acceptats ${ }^{27}$.

El 5 d'abril de 1337, el Cerimoniós intervingué a favor del tonsurat solter Berenguer Llobet, jurisperit de Barcelona, perquè actués com a advocat. Llobet també era dels que estaven compresos en la prohibició. Però el rei ordenà que prestés el jurament $\mathrm{i}$ fos admès ${ }^{28}$.

\footnotetext{
${ }^{24} \mathrm{ACA}, \mathrm{C}$, reg. 483 , fol. 204 r.-v.

${ }^{25} \mathrm{ACA}, \mathrm{C}$, reg. 487 , fols. 162 v. $-163 \mathrm{r}$.

${ }^{26} \mathrm{ACA}, \mathrm{C}$, reg. 858 , fol. $40 \mathrm{v}$.

${ }^{27} \mathrm{ACA}, \mathrm{C}$, reg. 856 , fol. 66 r.; reg. 861 , fol. 214 r.

${ }^{28} \mathrm{ACA}, \mathrm{C}$, reg. 861 , fol. $202 \mathrm{v}$.
} 
El 30 de maig de 1337, el mateix rei disposà que, si Bernat Puig, tonsurat solter, volia continuar exercint com a notari, havia de prestar el jurament ${ }^{29}$.

El 22 d'octubre de 1337, el Cerimoniós ordenava al veguer i al batlle de Barcelona que permetessin al jurisperit de Barcelona, Francesc de Montjuïc, continuar actuant com a advocat, malgrat estar comprès en la prohibició vigent, ja que era un tonsurat solter $^{30}$. Tan sols se li havia d'exigir el jurament.

Casos semblants foren el del notari de Vic, Bernat de Brull ${ }^{31}$; el d'Arnau de Llivià, notari de Barcelona ${ }^{32}$; de Guillem d'Illa ${ }^{33}$; de Pere Relat $^{34}$; de Pere Borrell ${ }^{35}$; de Pere d'Om ${ }^{36}$; i d'Arnau Canyadell ${ }^{37}$. Tots eren, així mateix, notaris de Barcelona, els quals, pel fet de ser tonsurats solters, malgrat que no ostentessin la tonsura, incorrien en la prohibició; però, prestant el jurament, es solucionava el problema.

El rei també va intervenir perquè Simó Esteve, jurisperit de Granollers $^{38}$, Bartomeu Plana, llicenciat en lleis $^{39}$, Pere Rovira, jurisperit de Barcelona ${ }^{40}$, Bernat Olivera, jurisperit de Corró d'Avall (Vallès Oriental) $)^{41}$, i Pere Civader, llicenciat en lleis $^{42}$, poguessin exercir els oficis d'advocar i de jutjar, amb la condició de prestar el jurament de no acollir-se al privilegi clerical.

En tots els casos que hem mencionat fins ara, ens trobem davant de persones tonsurades, solteres, que no ostentaven la tonsura. Ara se'ns

\footnotetext{
${ }^{29} \mathrm{ACA}, \mathrm{C}$, reg. 861 , fol. 259 r.-v.

${ }^{30} \mathrm{ACA}, \mathrm{C}$, reg. 862, fol. $56 \mathrm{v}$.

${ }^{31} \mathrm{ACA}, \mathrm{C}$, reg. 862, fol. 125 r. (1337, gener, 9).

${ }^{32} \mathrm{ACA}, \mathrm{C}$, reg. 862 , fols. 111 v.-112 r. (1338, gener, 10).

${ }^{33}$ ACA, C, reg. 863, fol. 200 v. (1338, abril, 2).

${ }^{34} \mathrm{ACA}, \mathrm{C}$, reg. 863, fol. 243 v. (1338, abril, 25).

${ }^{35} \mathrm{ACA}, \mathrm{C}$, reg. 864 , fol. 23 v. (1338, maig, 4).

${ }^{36} \mathrm{ACA}, \mathrm{C}$, reg. 867 , fols. 220 v. -221 r. (1339, novembre, 5).

${ }^{37} \mathrm{ACA}, \mathrm{C}$, reg. 873 , fol. 146 r. (1342, maig, 13).

${ }^{38} \mathrm{ACA}, \mathrm{C}$, reg. 869 , fol. 168 v. (1340, juliol, 29).

${ }^{39} \mathrm{ACA}, \mathrm{C}$, reg. 870 , fol. 27 r. (1340, octubre, 13).

${ }^{40} \mathrm{ACA}, \mathrm{C}$, reg. 872, fol. 67 r. (1341, setembre, 27).

${ }^{4}$ ACA, C, reg. 872, fol. 72 r. (1341, novembre, 10).

${ }^{42}$ ACA, C, reg. 873 , fol. 142 v. (1342, maig, 7).
} 
presenta un cas una mica diferent. Es tracta de Ramon Vinader, doctor en lleis, ciutadà de Barcelona. Vinader, que era conseller del rei, ostentava la tonsura i portava vestimentes clericals. El 24 d'abril de 1338, el sobirà féu amb ell una excepció. El rei manifestà que, per causes justificades, tot i que Vinader vivia, es comportava i es manifestava com un clergue, volia que li fos permès d'exercir els oficis d'advocat $i$ de jutge, malgrat les ordinacions existents que, "per a Vinader no comptaven, bé que no significava que es deroguessin" 4 .

Les autoritzacions reials que hem vist fins ara tenien com a finalitat que els interessats poguessin exercir els càrrecs d'advocat i de notari. Però també ens trobem amb un canviador: Es donava la circumstància que el canviador Bernat Bertran era un tonsurat casat, però que en el temps en què Alfons el Benigne promulgà les disposicions del 20 d'agost de 1328 era un tonsurat solter; per consegüent, llavors incorria en la prohibició d'exercir el seu ofici i, per aquesta raó, temia ésser-ne destituït. Per això, a petició seva, el 8 de desembre de 1340, Pere el Cerimoniós manà al veguer de Barcelona que li permetés d'exercir la seva professió i d'estar en possessió dels capbreus inherents a l'ofici, ja que era un tonsurat casat i no portava la vestimenta clerical ni mostrava la tonsura; però no fou pas dispensat de jurar que no s'acolliria a cap privilegi clerical ${ }^{\text {H4 }}$. Com hem vist, a la pràctica, tots els tonsurats, tant solters com casats, podien ocupar càrrecs públics si es comprometien a no acollir-se a cap privilegi clerical.

Situacions com les que hem mencionat sovintejaren fins l'any 1342. Però, a partir d'aquesta data, almenys pel que fa als clergues notaris, s'establí que prestessin aquest jurament de no acollir-se a cap privilegi clerical, de manera sistemàtica, en ser constituïts com a tals.

Aquesta qüestió relativa a l'esmentat jurament i el compromís de pagar la multa corresponent si no el complien - multa que, a partir de Pere el Cerimoniós i per a tota la Corona d'Aragó va quedar fixada en 300 morabatins-, ha estat estudiada molt detalladament per Albert Torra i Pérez en un documentat treball titulat Los registros "notariorum" de la cancilleria

\footnotetext{
${ }^{43}$ ACA, C, reg. 863, fols. 233 v. -234 r.: "concedinus vobis Raimundo Vinaterii ut quamdiu tonsuram et vestes portaveritis clericales et pro clerico vos gesseritis, admitamini et admitti possitis ad officium iudicandi et advocandi et alia quecumque officia publica...non obstantibus ordinacionibus editis .. quibus per hanc concessionem, quantum ad vos, volumus derogari, mandantes vicario et baiulo Barchinone, necnon rectori collegii advocatorum Barchinone...quam hanc concessionem quam... ex iustis causis, vobis facimus, firmam habeant...".

${ }^{44}$ ACA. C, reg. 870, fol. $101 \mathrm{v}$.
} 
$\operatorname{aragones}^{45}$. La investigació d'Albert Torra l'ha portat a la conclusió que, a partir del 1342, tots els notaris de nova creació, sistemàticament, havien de comprometre's a no recórrer a la justícia eclesiàstica sota la multa corresponent; i aquest jurament es recollia, a partir del 1351, en un protocol anomenat "firmarum et obligationum notariorum", pràctica que es mantingué fins al final del segle XVII ${ }^{46}$.

\section{Els CleRgues EN EL GOVERN DE LES CiUtATS}

Als clergues, també els era prohibit de formar part dels governs de les ciutats. Les ordinacions d'Alfons el Benigne del 20 d'agost de 1328 ho deien ben clarament: "clericus non coniugatus qui coronam habeat, licet eam non portet set laycaliter incedat, non admitatur seu eligatur ad officium tabellionatus, iurisdiccionis ordinarie, assessorie vel regiminis civitatis vel aliquid aliud seculare officium publicum quod publicum auctoritate et utilitate existunt, cum talia debeant esse clericos interdicta" ${ }^{47}$.

Els primers de protestar contra aquesta disposició, pel que es referia al govern de les ciutats, foren els consellers de Barcelona, els quals, cap al final de l'any 1329, manifestaren al rei Alfons que alguns que havien rebut la tonsura dubtaven si podrien ser elegits o no per a formar part del Consell de Cent Jurats, la qual cosa consideraven perjudicial per a la ciutat. El rei escoltà la queixa dels consellers de Barcelona i, el 16 de gener de l'any 1330 , des de València, concedí als consellers i als prohòmens barcelonesos que els tonsurats, si vivien com a laics, poguessin formar part del Consell de Cent. Això ja constituïa una excepció a la normativa ${ }^{48}$.

\footnotetext{
${ }^{45}$ Publicat a la revista "Napoli Nobilissima", XXXIII/III-VI (Nàpols, 1994), pp. 179-194.

${ }^{46} \mathrm{~A}$. TORra, op. cit., pp. 179-184.

${ }^{47} \mathrm{ACA}, \mathrm{C}$, reg. 520 , fols. 174 r.-v.

48"...hesitatur ac dubitatur per nonnullos quod habentes tonsuram non possunt eligi ac esse de numero centum juratorum...cumque vos, consiliarii ac probi homines supradicti asseratis dictam ordinacionem esse vobis nocivam super hoc ac in dampnum civitatis redundare, supplicatum, propterea, fuit nobis pro parte vestri consiliariorum vobis super hiis remedium adhiberi. Ideo...declaramus quod habentes ac defferentes tonsuram, dumtamen laycaliter vixerint et incesserint, assumantur et eligantur et eligi et assumi possint in numero centum juratorum..." [ACA, C, reg. 480 , fols. 40 v. -41 r. Ed. A.M. ARAGÓ y M.M. CosTA, Privilegios reales concedidos a la ciudad de Barcelona, "Colección de Documentos inéditos del Archivo de la Corona de Aragón", XLIII, Barcelona, 19XX, p. 51, n 102. Citen F. CARRERAS Y CANDI, La ciutat de Barcelona, a "Geografia General de Catalunya", dirigida per F. CARRERAS Y CANDI,
} 
Uns quants anys més tard, regnant ja Pere el Cerimoniós, es plantejà una situació semblant a Lleida.

La qüestió era que, a Lleida, cada any, eren elegits quatre cònsols o paers per al govern de la ciutat, els quals, al final del seu mandat, estaven obligats a tenere tabulam, és a dir, a retre comptes de la seva gestió. Podia donar-se la circumstància que alguns d'aquests paers fos un ciutadà solter, tonsurat, que portés vestimenta clerical. En aquest cas, no se li podia aplicar la justícia reial per les seves infraccions sinó que havia de ser jutjat pels tribunals eclesiàstics, la qual cosa infringia les ordinacions existents i perjudicava els ciutadans. Com que el rei volia mantenir la indemnitat de la ciutat de Lleida i, a més, considerava que l'ofici de paer havia de ser exercit per persones laiques, casades i sotmeses a la jurisdicció reial, el 16 de maig de 1351, ordenà al veguer i cort de Lleida i del Pallars, al batlle de Lleida i a tots altres oficials reials que, en el cas que fossin elegides com a paers persones solteres, tonsurades, que portessin vestits clericals i no sotmeses a la jurisdicció reial, no les confirmessin ni les admetessin en el càrrec ${ }^{49}$. En aquest cas, la prohibició era rotunda i no hi valia el jurament de no acollir-se a la legislació eclesiàstica.

\section{ElS CLERGUES I LA PRÀCTICA DELS OFICIS}

Fins ara hem tractat de la qüestió relativa als clergues que ocupaven càrrecs públics, però també els trobem practicant diferents oficis, com, per exemple, el de mercader o altres artibus mecanicis. Pel que fa als oficis, succeïa a la inversa. Es donava la circumstància que alguns mercaders, carnissers, drapers, etc. es feien practicar la tonsura "en gran desprestigi de la clerecia", atès que la seva intenció no era la d'arribar mai a rebre els Ordes sagrats sinó la d'acollir-se als privilegis clericals i eludir d'aquesta manera la justícia reial, si arribava el cas de cometre algun delicte tot exercint l'ofici. Com que aquesta pràctica esdevingué cada vegada més generalitzada, Pere el Cerimoniós, el 6 de març de 1374, decidí a tornar a posar en vigor un edictum seu estatutum de Jaume II que ja, en el temps del

Barcelona, s.a., p. 669, nota 1806; J. MUTGÉ VIVES, La ciudad de Barcelona durante el reinado de Alfonso el Benigno (1327-1336), Madrid-Barcelona, 1987, p. 133, nota 165].

${ }^{49 "}$ cum per laycos vel coniugatos, tonsuram vel habitum clericalem minime defferentes, ipsum oficium exerceri velimus totaliter" (ACA, C, reg. 667, fol. 16 r.-v. 1351, maig, 16). 
regnat d'aquest darrer sobirà, anava encaminat, precisament, a evitar aquests abusos, malgrat que - com ja hem dit al començament d'aquest treball- el Concili Provincial de Lleida del 1229 ja ho havia prohibit. La data esmentada, doncs, Pere el Cerimoniós manà als governadors, veguers, batlles i tots altres oficials reials de Catalunya que l'edicte fos pregonat en llengua vulgar, per a més fàcil coneixement de tothom. Aquesta disposició deia textualment:

\begin{abstract}
alcú usant de offici de mercaderia o d’altres arts mecàniques no gosàs usar de ofici de mercaderia o d art mecànica ab algun clergue o portant tonsura, venent o comprant o en altra manera no gosàs tenir dexeble algú clergue o tonsurat per aprendre usar offici de mercaderia o art mecànica no atorgada a clergues, sots pena de cinc diners d'or per cascuna vegada que sia fet contra ${ }^{50}$.
\end{abstract}

Aquesta pragmàtica de Jaume II fou aprovada pel Concili de Tarragona del 1331, en el qual s'establí que tots els clergues casats o tonsurats estaven obligats a presentar-se als bisbes de les seves diòcesis, els quals els amonestarien perquè portessin la tonsura i els hàbits clericals $i$ perquè s'abstinguessin de practicar feines "deshonestes", com ho eren els oficis de carnicer, taverner, tafurer, bastaix, joglar, carboner, ferrer, cuirasser o pirata, aquest ni tan sols en el cas de lluitar contra els infidels, i de participar en guerres. El pontífex Gregori XI (1370-1378) considerà raonable i justa aquesta ordinació i expedí una butlla segons la qual aquests falsos clergues no podrien ser defensats per cap privilegi clerical sinó que haurien de respondre a la justícia reial ${ }^{51}$.

De la pena imposada als contraventors, una part seria per a l'acusador i les dues terceres parts restants serien per a l'erari reial ${ }^{52}$.

Malgrat que aquesta ordinació fou posada en vigor pel Cerimoniós el 6 de març de 1374, no es devia complir. Almenys, així ho fa suposar el fet que, quatre anys més tard, el 12 de setembre de 1378 , la promulgà una

\footnotetext{
${ }^{50}$ ACA. C, reg. 1090, fols. 95 v. -96 v. 1374, març, 6.

"Il Ibidem.

sibidem
} 
altra vegada, tot manant als seus oficials que aquesta ordinació es publiqués cada any solemnement, sota pena de la pèrdua de l'oficis? ${ }^{53}$.

\section{RÉSUMÉ}

Dans cet article, on étudie la question que se posait très fréquemment au XIV" siècle à cause de lexercice de charges publiques. comme avocats. notaires ou conseillers des villes par les cleres tonsurés.

Les souverains de la Couronne d'Aragon promulgaient diverses pragmatiques pour réglementer cette situation et éviter que, en cas de commetre un délit en l'exercice du charge. les tonsurés furent jugés par une cour ecclésiastique et éludèrent la justice royale. plus sévère. On est analisée aussi la pratique de métiers artisans par les clerces tonsurés.

\section{SUMMARY}

This article is devoted to study, in the area of the Crown of Aragon and during the XIV th century, of a problem that frequently arose in the Middle Ages: public offices, such as those of lawyers, notaires or councillors of cities. etc.. were held by clergymen. especially by those who had only obtained the first clerical degree (tonsure). although it was prohibited hy ecclesiastical laws. The catalano-aragonese Kings published some royal ordinances in order to regulate that situation and to avoid that. in case the tonsurates committed a fault, were judged by ecclesiastical court and could escape from royal justice, which was more severe.

The activities as artisans of these tonsurates are also studied in this article.

${ }^{53}$ ACA, C, reg. 1098, fols. 170 r.-172 v. 1378, setembre, 12.

Sobre qüestions relatives a la clerecia secular, vegeu, en aquest mateix volum, els treballs de Lluis CIFUENTES-Gemma ESCRIBÀ, El monopoli de la paraula: cura d'àmimes, educació $i$ fe pública a la parròquia de Santa Maria de Piera durant la Baixa Edat Mitjana. pp. 789-820; i el de Flocel SABATÉ, L'església secular catalana al segle XIV: la conflictirar relació social, pp. 757-788. 